\title{
Impact of Climate Change on Food Security of Rural Householders in Gibaish Locality of West Kordofan State, Sudan
}

\author{
Elkhalil E. Breima ${ }^{1}$, Makeen A. Makeen ${ }^{2}$, Abdelaziz A. Elshiekh ${ }^{3}$, Fathi H. Balldo ${ }^{4}$, Maruod E. Maruod ${ }^{4, *}$ \\ ${ }^{1}$ Department of Agricultural Economics, Agricultural Research Corporation, Zalingei Research Station, Sudan \\ ${ }^{2}$ Vice-chancellor Office, Peace University, Sudan \\ ${ }^{3}$ Deanship of Academic Affairs, University of Kordofan, Sudan \\ ${ }^{4}$ Department of Agricultural Economics and Rural Development, Faculty of Natural Resources and Environmental Studies, University of \\ Kordofan, Sudan
}

Copyright $(2016$ by authors, all rights reserved. Authors agree that this article remains permanently open access under the terms of the Creative Commons Attribution License 4.0 International License

\begin{abstract}
The current study focused on the linkage between climate change and food security of rural householders in Gibaish locality, western Sudan. The overall objective was to explore the level of food security and impacts of climate change variables on the food security of rural householders in the study area. Multistage-stratified random sampling technique was used to select 70 households. Data were obtained from both primary and secondary sources and analyzed using descriptive statistics, household economy approach, linear programming, partial crop budget, dominance analysis, marginal analysis, sensitivity analysis, linear regression and correlation coefficients analysis were employed. In this study, the household's economy approach for the daily energy received per person per day in $\mathrm{K}$. calories was estimated as 2105 . With respect to WHO, minimum rate of $2300 \mathrm{~K}$. calories per person per day was set as standard level. Therefore, this result implies that the household is marginally food insecure. Linear programming results indicated that the maximum combination that maximized farmer's income was attained by millet, groundnut and okra crops combination with a total SDG 11,148 (1 \$ = SDG 6.64). When taking into consideration the household's food consumption behavior it was found that increase over decrease was lesser by $184 \%$. These results ensured that the proportional combination of the food items consumed at local level would not enable the households to meet their minimum energy requirement for a healthy and active life. It was also noted that climatic variation in year 2013 cropping season has negative impact on food security situation. Partial crop budget revealed that all crops gave positive net returns. Groundnut and okra gave maximum net benefits of SDG 2056 and SDG 1380, respectively. Dominance analysis showed that Gum Arabic and Roselle were dominated due to their lower net field benefits as
\end{abstract}

compared to other treatments. Results of marginal analysis showed that maximum marginal rate of return of $13733.4 \%$ was obtained by groundnut). It is noted that farmers with poor resources can accomplish returns of SDG 1.00 benefits by sowing groundnut to obtain additional SDG 137.3. Sensitivity analysis that assumed costs over run and benefits shortfall revealed that groundnut and sorghum combination was of high Marginal Rate of Return (MRR) of $12,484.9,12,360$ and 537.9 and SDG 532.5, respectively. Linear regression ensured that maximum average temperature significantly $(\mathrm{P} \leq 0.05)$ affected millet production. Other food production crops were not affected by climatic factors. Correlation coefficients showed increasing temperature and rainfall fluctuation was reported as major threats to food production. Sorghum was negatively $(-0.705, p=0.01)$ correlated with time and growing period, millet moderately correlated with time (-0.494). However, sesame, groundnut, Roselle, cowpea and watermelon were weakly and negatively correlated with time. Consequently, millet $(-0.385)$, sorghum $(-0.128)$, sesame $(-0.266)$, groundnut $(-0.185)$, Roselle $(0.242)$, cowpea (0.185) and watermelon (0.034) were not significantly affected, and it has negative and positive minimum correlation with average maximum temperature.

Keywords Climate Change, Regression, West Kordofan, Linear Programming, Partial Budget

\section{Introduction}

FAO (2012) stated food security is likely to be affected by climate change (CC) in several ways: food security 
depends not only on the direct impact of $\mathrm{CC}$ on food production, but also on its indirect impacts on human development, economic growth, trade flows, and food aid policy. Agriculture is the practice of crop cultivation and livestock keeping. The choice of what to produce and how to produce is determined by the culture, traditions, market, water supply, climate, soil condition, plot size and distance from home (Denen, 2013). Gibaish locality lies in the western side of the state. According to FAO (2008), food security is the outcome of food system processes all along the food chain. Climate change will presumably affect food security through its impacts on all components of global, national and local food systems. Holt et al (2000) has pointed out that the aim of Household Economy Approach (HEA) was to find a method that could indicate the likely effect of crop failure or other shocks on future food supply. Food security is a situation that exists when all people at all times have physical, social, and economic access to sufficient, safe and nutritious food that meets their dietary needs and food preferences for an active and healthy life (Lobell, 2012). With reference to Yue, (2013) linear programming (LP) is a powerful analytical tool that can be used to determine an optimal solution that satisfies the constraints and requirements of the current situation. This method consists of three quantitative components: (1) objective function (maximization of profit or minimization of costs); (2) constraints (limitation of production sources); and (3) decision variables. The multiple linear regression models are an extension of a simple linear regression model to incorporate two or more explanatory variable in a prediction equation for a response variable. Multiple regression modeling is nowadays a mainstay of statistical analysis in most fields because of its power and flexibility (Brant, 2007).

Gibaish locality is located in the western part of the state with an estimated population of 929758 persons whom primarily rely on agricultural activities for their living. The area is occupied by arid agro-climatic zone. The study area receives an annual summer rainfall of $250 \mathrm{~mm}$ to $450 \mathrm{~mm}$. The rainy season begins at about the end of June and lasts until early October, while the dry season begins in last October and ends in early June. Temperature is relatively lower and ranges between $23^{\circ} \mathrm{C}$ and $25^{\circ} \mathrm{C}$ in the wet season throughout the Ataman except in March - June when sun shine reached and ranged from $35^{\circ} \mathrm{C}$ to $40^{\circ} \mathrm{C}$.

Virtually all householders in the study area rely solely on agricultural activities for their livelihoods. Small holders, rainfed subsistent farming is widely practiced. Groundnut, sesame, watermelon and Roselle are cultivated as cash crops added to Gum Arabic tree plantations. Millet and sorghum are grown as staple food crops. Food gaps and shortages are frequently encountered due to biotic and a biotic factors that curb their crop production. The overall objective of the current study was to evaluate the level of food security and impacts of climate change variables on the food security of rural householders in the study area.

\section{Materials and Methods}

The overall approach and methodology for the livelihood survey work carried out in Gibaish locality, West Kordofan State, based on both and primary secondary sources of data for climate change impact on food security. In particular, the field level householder questionnaires designed to gather information through multi-stage stratified random sample technique for 78 selected households. Climatic data on Average temperature and total rainfall were obtained from Khartoum and Elnuhood meteorological stations for statistical series data (2000 -2013). While crop yield data were sourced from Ministry of Agriculture in North and western Kordofan states.

Crops grown are watermelon, Gum Arabic, groundnut and Roselle

Descriptive statistics, Household Economy Approach, Linear programming, Partial crop budget, and multiple linear regression and correlation coefficient models were applied.

\subsection{Descriptive Statistics}

Descriptive statistics are most often used to examine, central tendency (location) of data, i.e. where data tend to fall, as measured by the mean, median, and mode. Dispersion (variability) of data, i.e. how spread out data was, as measured the variance and its square root, the standard deviation. skew (symmetry) of data, i.e. how concentrated data was at the low or high end of the scale, as measured by the skew index. kurtosis of data, i.e. how concentrated data was around a single value, as measured by the kurtosis index.

\subsection{Household Economy Approach}

Household economy approach is a method of analyzing the impact of crop failure and other shocks on household income and access to food (Holt et al 2000).

\subsection{Linear Programming Model}

Kernighan et al (2003) ensured that linear programs are particularly important because they accurately represent many practical applications of optimization. The simplicity of linear functions makes linear models easy to formulate, interpret, and analyze. They are also easy to solve; if you're a problem can be expressed as a linear program, even in thousands of constraints and variables, then one can be confident of finding an optimal solution accurately and quickly.

\subsection{Partial Crop Budget}

Partial budgeting is a planning and decision-making framework farm business owners can use to compare the costs and benefits of alternatives they face. It allows 
producers to get a better handle on how a decision will affect the profitability of the business enterprise and the farm itself. This publication explains how to use partial budgeting and explains its benefits in making farm business decisions. A partial budget helps farm owners/managers to evaluate the financial effect of incremental changes. A partial budget only includes resources that subject to changes. It does not consider the unchangeable resources in the business. Only the change under consideration is evaluated for its ability to increase or decrease income in the farm business (Tigner, 2006).

\subsection{Multiple Linear Regressions}

The multiple linear regression models are an extension of a simple linear regression model to incorporate two or more explanatory variable in a prediction equation for a response variable. Multiple regression modeling is now a mainstay of statistical analysis in most fields because of its power and flexibility (Brant, 2007).

\subsection{Correlation Model}

A correlation coefficient is a statistical measure of the degree to which changes to the value of one variable predict change to the value of another. In positively correlated variables, the value increases or decreases in tandem, whereas for negatively correlated variables, the value of one increases as the value of the other decreases (Wigmore, 2013).

\section{Results and Discussion}

Socioeconomic characteristics of education level in the study area revealed that $84 \%$ of sample householders were exposed to some sort of education. This observation meant presence of literate farmers in the study area equipped with additional local knowledge to cope with climate change and food insecurity than those who had no formal education. These results reconciled with Hamilton (2010) whose opinion that climate change has decreased with education among Republicans, Figure 1.

Household economy approach results founded that the average quantity of energy received by a single householder per a week during summer, autumn and winter was calculated as being SDG 31404. While the daily energy received per person per day was found to be SDG 2105. This results highlight that household is marginally food insecure, (Table 1) based on the standard set by WHO (2300 K. calories).

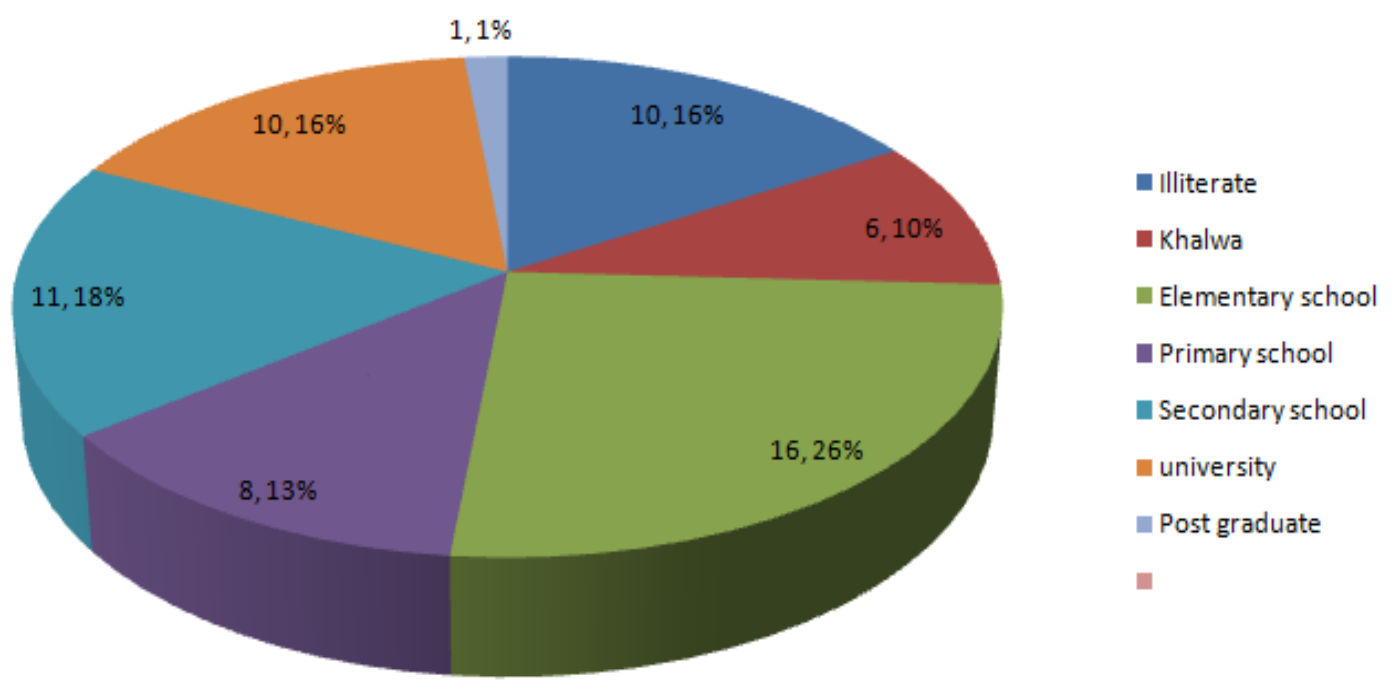

Source: HH survey 2014

Figure 1. Socioeconomic distribution of education level in the study area 
Table 1. Household Weekly minimum Food Need and the equivalent K.cal, Gibaish locality

\begin{tabular}{|c|c|c|c|c|c|c|c|c|c|c|}
\hline \multirow{3}{*}{ Food items } & \multicolumn{10}{|c|}{ Seasons } \\
\hline & \multicolumn{4}{|c|}{ Summer } & \multicolumn{3}{|c|}{ Autumn } & \multicolumn{3}{|c|}{ Winter } \\
\hline & $\mathrm{Kcal} / \mathrm{kg}$ & qt.kg & total Kcal & \%share & qt.kg & total Kcal & \%share & qt.kg & total Kcal & $\%$ share \\
\hline Millet & 3350 & 9 & 30150 & 27.1 & 9.3 & 31155 & 26.3 & 10 & 33500 & 27.0 \\
\hline Sorghum & 3350 & 5.5 & 18425 & 16.6 & 5.9 & 19765 & 16.7 & 6.6 & 22110 & 17.8 \\
\hline wheat & 3320 & 4.7 & 15604 & 14.0 & 4.8 & 15936 & 13.5 & 4.8 & 15936 & 12.9 \\
\hline Meat & 2020 & 2.9 & 5858 & 5.3 & 2.9 & 5858 & 4.9 & 2.9 & 5858 & 4.7 \\
\hline Milk & 660 & 3.3 & 2178 & 1.9 & 3.3 & 2178 & 1.8 & 3.3 & 2178 & 1.8 \\
\hline Sugar & 4000 & 4.0 & 16000 & 14.4 & 4.0 & 16000 & 13.5 & 4.2 & 16800 & 13.6 \\
\hline Tea & 1080 & 0.35 & 378 & 0.3 & 0.32 & 346 & 0.3 & 0.32 & 346 & 0.3 \\
\hline Coffee & 685 & 0.51 & 349 & 0.3 & 0.52 & 356 & 0.3 & 0.52 & 356 & 0.3 \\
\hline Onion & 410 & 4.1 & 1681 & 1.5 & 4.4 & 1804 & 1.5 & 4.4 & 1804 & 1.5 \\
\hline Oil & 8840 & 2.3 & 20332 & 18.3 & 2.8 & 24752 & 20.9 & 2.8 & 24752 & 19.9 \\
\hline Dry Okra & 350 & 0.81 & 284 & 0.3 & 0.81 & 284 & 0.2 & 0.82 & 284 & 0.2 \\
\hline Total & & & 111239 & & & 118434 & & & 123924 & \\
\hline $\begin{array}{c}\text { Per } \\
\text { person/day }(8)\end{array}$ & & & & & & & & & 2105 & \\
\hline
\end{tabular}

Source: HHS survey 2014

Results of linear programming model ensured that Production of one hectare requires 18, 20, 28, 17, 4, 28, 31, 18, and 60 , $171,176,270,122,122,85,32,23$ and 45 of labor man hours and working capital for the above decision variables, respectively. A total of 383 man hours of labor were potentially available for providing family workers during the cropping season. Groundnut is more profitable with a gross margin of SDG6267.27.The minimum requirement of household's food expenditure for maintains a livelihood was found to be SDG31, 404. The maximum combination that maximizes farmers' income was reached by millet, groundnut and okra with a total SDG 11,148 . When taking into consideration the household's food consumption behavior it was found that increase over decrease was lesser by $182 \%$. These results indicated that the proportional combination of the food items consumed at local level will not enable the household to meet minimum energy requirement for a healthy and active life. It is also noted that climatic variation in year 2013 cropping season negatively impact food security situation, as shown in Table 2. Partial crop budget showed that all treatments gave positive net return. A high return (SDG 2056) was obtained by groundnut and okra (SDG1380). This result implies that profitability would make this farming practice both beneficial and desirable (Table 3 ). The dominance analysis showed that Gum Arabic and Roselle were dominant due to their lower net field benefits as compared to other crop combinations (Table 4). Marginal analysis, in turn, showed that maximum MRR of $13,733.4 \%$ was obtained by groundnut. It is noted that farmers with poor resources can accomplish returns of SDG 1.00 benefits by sowing the groundnut to obtain additional SDG 137.3, (Table 5). Sensitivity analysis that assumed costs over run and benefits shortfall revealed that groundnut and sorghum has high MRR of SDG12, 484.9, 12360, 537.9 and 532.5, respectively. This result indicated that these crops were not sensitive to climate variation, (Tables 6 and 7), respectively.

Table 2. Optimal solution or farm plan for the base model in SDG/ha

\begin{tabular}{ccccc}
\hline Crop & Coefficients & Area/ha & Optimal solution & Final value SDG \\
\hline millet & 701 & 4.908075438 & 3440.56 & 3440.56 \\
sorghum & 820 & 0 & 0 & 0 \\
Groundnut & 2056 & 3.048281754 & 6267.27 & 0267.27 \\
Sesame & 944 & 0 & 0 & 0 \\
Roselle & 152 & 0 & 0 & 0 \\
Watermelon & 536 & 0 & 0 & 0 \\
Cowpea & 614 & 0 & 1440.23 & 0 \\
Okra & 1380 & 1.043642807 & 0 & 1440.23 \\
Gum Arabic & 302 & 0 & & 0 \\
Total GM & & &
\end{tabular}

Source: HHS survey 2014, SDG= Sudanese Genih 
Table 3. Partial crop budget analyses, (averages taken to represent season 2013 for2012/2013- 2013/2014 cropping seasons)

\begin{tabular}{ccccc}
\hline Crop & Yield kg/ha & Gross field benefit & Costs that vary & Net returns SDG/ha \\
\hline Millet & 123 & 867 & 166 & 701 \\
Sorghum & 164 & 910 & 90 & 820 \\
Groundnut & 592 & 2155 & 99 & 2056 \\
Sesame & 313 & 2164 & 1220 & 944 \\
Roselle & 37 & 271 & 119 & 152 \\
Watermelon & 116 & 578 & 42 & 536 \\
Cowpea & 205 & 1311 & 697 & 614 \\
Okra & 247 & 4323 & 2943 & 67 \\
Gum Arabic & 548 & 369 & & 302 \\
\hline
\end{tabular}

Source: HHS survey 2014

Table 4. Dominance analysis, (averages taken to represent season 2013 for 2012/2013-2013/2014 cropping seasons)

\begin{tabular}{ccccc}
\hline Crop & Yield kg/ha & Gross field benefit & Costs that vary & Net returns SDG/ha \\
\hline T1 watermelon & 116 & 578 & 42 & 536 \\
T2 Gum Arabic & 548 & 369 & 67 & $302 \quad$ D \\
T3 Sorghum & 164 & 910 & 90 & 820 \\
T4 Groundnut & 592 & 2155 & 99 & 2056 \\
T5 Roselle & 37 & 271 & 119 & $152 \quad$ D \\
T6 Millet & 123 & 867 & 166 & 701 \\
T7 Cowpea & 205 & 1311 & 697 & 614 \\
T8 Sesame & 313 & 2164 & 1220 & 944 \\
T9 Okra & 247 & 4323 & 2943 & 1380 \\
\hline
\end{tabular}

Source: HHS survey 2014

Table 5. Marginal analysis (averages taken to represent season 2013 for 2012/2013-2013/2014 cropping seasons)

\begin{tabular}{|c|c|c|c|c|c|}
\hline Crop & Costs that vary & Marginal costs & Net returns SDG/ha & $\begin{array}{c}\text { Incremental net } \\
\text { benefit }\end{array}$ & \multirow{2}{*}{$\mathrm{MRR}=\mathrm{V} / \mathrm{III} * 100$} \\
\hline I & II & III & IV & $\mathrm{V}$ & \\
\hline T1watermelon & 42 & - & 536 & - & \\
\hline T3Sorghum & 90 & 48 & 820 & 284 & 591.7 \\
\hline T4 Groundnut & 99 & 9 & 2056 & 1236 & 13733.4 \\
\hline T6 Millet & 166 & 67 & 701 & -1355 & $\mathrm{D}$ \\
\hline T7 Cowpea & 697 & 531 & 614 & -87 & $\mathrm{D}$ \\
\hline T8 Sesame & 1220 & 523 & 944 & 330 & 63.1 \\
\hline T9 Okra & 2943 & 1723 & 1380 & 436 & 25.3 \\
\hline
\end{tabular}

Source: HHS survey 2014

Table 6. Sensitivity analysis, of costs overrun (averages taken to represent season 2013 for 2012/2013-2013/2014 cropping seasons)

\begin{tabular}{|c|c|c|c|c|c|}
\hline Crop & Costs that vary & Marginal costs & Net returns SDG/ha & $\begin{array}{c}\text { Incremental net } \\
\text { benefit }\end{array}$ & \multirow{2}{*}{$\mathrm{MRR}=\mathrm{V} / \mathrm{III} * 100$} \\
\hline I & II & III & IV & $\mathrm{V}$ & \\
\hline T1watermelon & 46.2 & - & 536 & - & \\
\hline T3Sorghum & 99 & 52.8 & 820 & 284 & 537.9 \\
\hline T4 Groundnut & 108.9 & 9.9 & 2056 & 1236 & 12484.9 \\
\hline T8 Sesame & 1342.0 & 1233.1 & 944 & -1112 & $\mathrm{D}$ \\
\hline T9 Okra & 3237.3 & 1895.3 & 1380 & 436 & 23.0 \\
\hline
\end{tabular}

Source: HHS survey 2014 
Table 7. Sensitivity analysis, of benefit shortfall, (averages taken to represent season 2013 for 2012/2013-2013/2014 cropping seasons)

\begin{tabular}{|c|c|c|c|c|c|}
\hline Crop & Costs that vary & Marginal costs & Net returns SDG/ha & Incremental net benefit & MPR $=$ V/LI* 100 \\
\hline I & II & III & IV & V & ИमКК- \\
\hline T1watermelon & 42 & - & 482.4 & - & \\
\hline T3Sorghum & 90 & 48.0 & 738.0 & 255.6 & 532.5 \\
\hline T4 Groundnut & 99 & 9 & 1850.4 & 1112.4 & 12360 \\
\hline T8 Sesame & 1220 & 1121 & 849.6 & -1000.8 & - \\
\hline T9 Okra & 2943 & 1723 & 1242.0 & 392.4 & 22.8 \\
\hline
\end{tabular}

Source: HHS survey 2014

Table 8. Regression analysis of total crop production across climatic variables

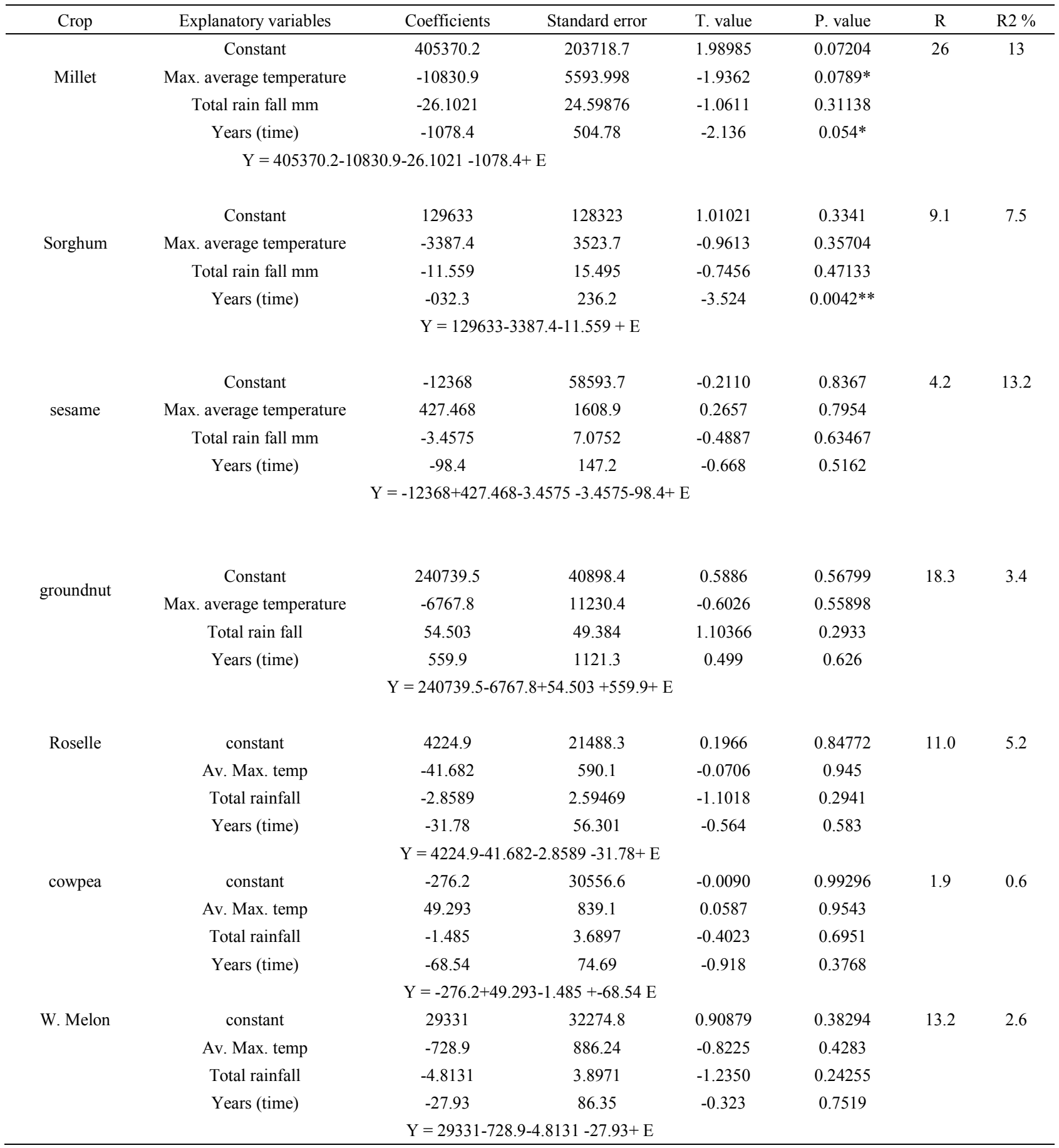


Table 9. Correlation analysis (r)

\begin{tabular}{ccccccccccc}
\hline Variables & millet & sorghum & sesame & g/nut & Roselle & cowpea & WM & years & $\begin{array}{c}\text { Av. max. } \\
\text { temp }\end{array}$ & $\begin{array}{c}\text { Total } \\
\text { RFL }\end{array}$ \\
\hline Years & -0.494 & $-0.705^{* *}$ & 0.117 & 0.341 & -0.070 & -0.190 & -0.047 & 1 & 0.304 & 0.418 \\
$\begin{array}{c}\text { Av. max. } \\
\text { temp }\end{array}$ & -0.385 & -0.128 & -0.266 & -0.185 & 0.242 & 0.183 & 0.034 & 0.304 & 1 & -0.347 \\
Total RFL & -0.130 & -0.162 & -0.231 & -0.362 & -0.387 & -0.179 & -0.354 & 0.418 & -0.347 & 1 \\
\hline
\end{tabular}

Source: HHS survey 2014, WM=watermelon, av. max. temp = average maximum temperature, $\mathrm{TRF}=$ total rainfall

Multiple regressions exhibited that maximum average temperature significantly $(\mathrm{P} \leq 0.05$, with $13 \%$ goodness of fit $)$ affected millet production. These results indicated that $13 \%$ of variation on millet food production/ security was related to maximum average temperature. It was probable that climatic variables don't affect other food production crops. This is might be attributed to other production factors such as lack of credit, access to agricultural extension services as stated by households. These results coincide with Yang et al (2015) who pointed out that descriptive statistics could not reflect climate change and variability among climate parameters. Results of trend analysis revealed significant $(\mathrm{P} \leq 0.05)$ positive trend shown upon millet while it is higher (at ten percent) in sorghum food crops. This implies that climate change all over the period of the study impacted production of such food crops. Whereas there is no impact between time and the remaining crops produced, (Table 8 ). Correlation coefficients showed that increasing temperature and rainfall fluctuations were regarded by households as major threats to agricultural production including food production. Sorghum food crop was negatively $(-0.705$, $\mathrm{p}=0.01$ ) correlated with time and growing period, whereas was millet moderately correlated with time (-0.494). However, sesame, groundnut, Roselle, cowpea and watermelon were weakly and negatively correlated with time. Consequently millet $(-0.385)$, sorghum $(-0.128)$, sesame (-0.266), groundnut (-0.185), Roselle (0.242), cowpea (0.185) and watermelon (0.034) were independent showing minimal negative and positive correlation with average maximum temperature. These results apparently indicate the importance of other intermingling factors such as soil fertility, access to credit and lack of improved technologies. This means that these crops require adequate minimum temperature to survive. The coefficients of food and other crop production across total rainfall were negatively correlated despite that they were not significant at 0.01 and 0.05 levels, (Table 9).

\section{Conclusions}

Socioeconomic indicators of households revealed that literate farmers in the study area were more successful in preventing and/or coping with climate change hazards and food insecurity than those who had no formal education. The maximum combination that maximized farmer's income indicated that the proportional combination of the food items consumed at local level would not enable the household to meet its minimum energy requirement for a healthy and active life. Partial budget ensured that all alternatives positively gave net returns and the minimum acceptable rate of returns can enable household farmers for further investment. Multiple linear regressions exhibited maximum average temperature significantly affected millet production. This is implies that $13 \%$ of variation on millet food production/ security was related to maximum average temperature. It is obvious that climatic variables didn't affect other food production crops. This might be attributed to other production factors such as lack of credit, access to agricultural extension services as stated by households. Correlation coefficient analysis displayed that increasing temperature and rainfall fluctuations were reported by households as major threats to agricultural production including food security.

\section{REFERENCES}

[1] Brant, R. (2007). Multiple linear regressions. P2

[2] Denen, A., T., (2013). Climate and grain crops yield in Kwara State, Nigeria. Department of Agricultural and Biosystems Engineering, Faculty of Engineering and Technology, University of IIorin, Nigeria. Journal of Emerging Trends in Engineering and Applied Science (JETEAS) 4 (5): 737-741. Scholar link Research Institute Journals (ISSN: 2141-7016). P 52.

[3] FAO, (2008). Climate change and food security: A Framework document. Food and Agricultural Organization of the United nations, Rome. P xi.

[4] FAO (2012). Potential impacts of climate change on food security in Mali. Natural Resources Management and Environment Department, Rome.

[5] Hamilton, L. (2010). Education, politics and opinions about climate change evidence for interaction effects. Springer Science + Business Media B.V.

[6] Holt, J., Seaman., J. Clarke, P. Boudreau. (2000). The household Economy Approach. A resource manual for practitioners. Save the Children Development Manual No. 6. Published by Save the Children 17 Grove Lane, London SE5 8 RD UK. P2.

[7] Kernighan, B. W. Fourer, R., and Brian, G. (2003). Linear programs: Objectives and constraints. P 129.

[8] Lobell, D and Burke, M. (2010). Climate Effects on food security: An Overview. Advances in Global Change Research 37, DOI: 10.1007/978-90-481-2953-9_2, Springer Science + Business Media, B.V. 
[9] Tigner, R. (2006). Partial Budgeting: A tool to Analyze Farm Business Changes, Nebraska Extension Educator.

[10] Wigmore, I. (2013). Correlation coefficient. Part of the business intelligence-business analytics glossary.
[11] Yang, M., Amin, R. Md., Zhang, J. (2015). Effect of climate change on the yield and cropping area of Major food crops: A case of Bangladesh. College of Economics and Management, Huazhong Agricultural University, Wuhan 430070, China press. 